\section{Endoscopic drainage of pancreatic fluid collections into fourth portion of duodenum: a new approach to disconnected pancreatic duct syndrome}

Pancreatic fluid collections may recur after successful endoscopic drainage [1 - 3], particularly in patients with underlying pancreatic duct abnormalities [4]. In addition, transgastric drainage of pancreatic tail collections may be impossible in patients with splenic vein thrombosis and gastric varices.

We treated five patients with recurrent pancreatic fluid collections of the pancreatic tail by endoscopic ultrasound-guided drainage of the collection into the fourth portion of the duodenum. All patients had previously undergone transmural, transpapillary, and/or percutaneous drainage of a pancreatic fluid collection and sub- sequently developed recurrent collections. Four patients met diagnostic criteria for disconnected pancreatic duct syndrome [4]. None of the collections were anatomically accessible to drainage through the proximal duodenum; four patients had splenic vein thrombosis with gastric varices.

Drainage was technically successful in all patients ( Fig. 1, 2), with resolution of the collection on CT or magnetic resonance scans. We placed 7-Fr and $10-\mathrm{Fr}$ double-pigtail plastic stents into the collections. No complications were observed. After stent removal, one patient underwent distal pancreatectomy for pancreati- tis, and another had a recurrent fluid collection treated with repeat endoscopic drainage into the fourth portion of the duodenum. The other patients remain well up to 34 months after stent removal. Follow-up imaging studies showed atrophy of the pancreatic tail in all cases.

Our experience demonstrates that drainage of pancreatic fluid collections into the distal duodenum under endoscopic ultrasound guidance is feasible and appears safe, and may provide extended benefit for some patients who would otherwise require distal pancreatectomy. The relatively thin duodenal wall may allow a prolonged or even persistently patent pancreaticoduodenal fistula to drain the pancreatic tail [5]. This approach may benefit patients with symptomatic collections and disconnected pancreatic duct syndrome.

Endoscopy_UCTN_Code_TTT_1AS_2AD

Competing interests: None
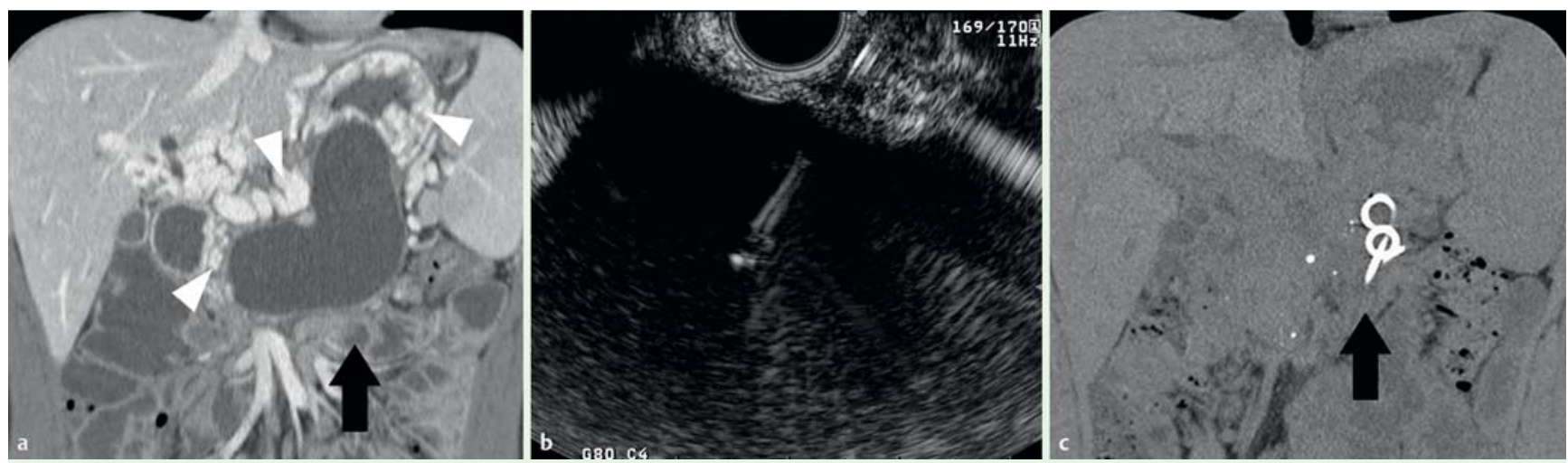

Fig. 1 Drainage of a recurrent fluid collection after necrotizing pancreatitis. a Contrast-enhanced CT shows a large pancreatic fluid collection. Gastric and duodenal varices (white arrowheads) are present, preventing transmural drainage in these locations. The fourth portion of the duodenum (black arrow) is adjacent to the fluid collection. $\mathbf{b}$ Endoscopic ultrasound image shows puncture of the collection with a 19-gauge needle from the fourth portion of the duodenum. c Unenhanced CT 8 weeks after drainage shows stents in place with resolution of the collection.
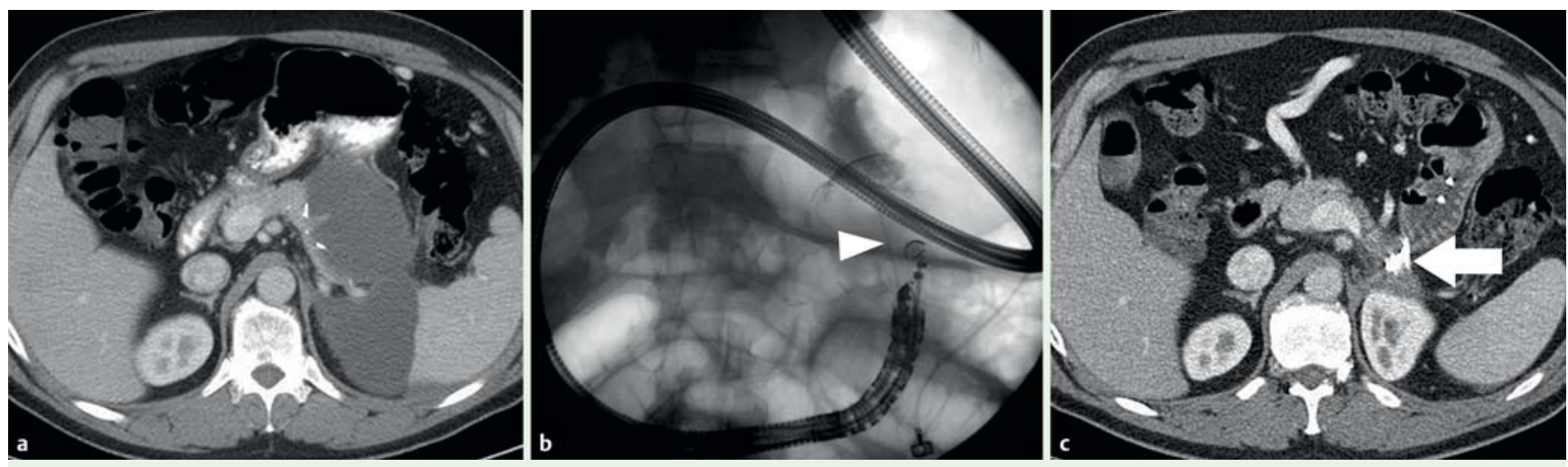

Fig. 2 Drainage of a recurrent fluid collection after injury of the pancreatic tail. a CT demonstrates a bilobed fluid collection and a pancreatic tail remnant adjacent to surgical clips. b Fluoroscopic view of an echoendoscope in the fourth portion of the duodenum. The collection has been punctured by a 19-gauge needle (white arrowhead) and contrast injected. c CT scan 6 weeks after drainage shows resolution of the collection. The shafts of the plastic stents traverse a pancreaticoduodenal fistula (white arrow). 


\section{N. Zhong ${ }^{1,2}$, M. Topazian², B. T. Peter-} $\operatorname{sen}^{2}$, T. H. Baron ${ }^{2}$, S. T. Chari ${ }^{2}$, F. C. Gleeson $^{2}$, M. J. Levy ${ }^{2}$, M. L. Kendrick ${ }^{3}$, S. S. Vege $^{2}$

1 Department of Gastroenterology, Qilu Hospital of Shandong University, Jinan, Shandong, China

2 Division of Gastroenterology and Hepatology, Department of Internal Medicine, Mayo Clinic, Rochester, Minnesota, United States

3 Department of General Surgery, Mayo Clinic, Rochester, Minnesota, United States

\section{References}

1 Hookey LC, Debroux S, Delhaye M et al. Endoscopic drainage of pancreatic-fluid collections in 116 patients: a comparison of etiologies, drainage techniques, and outcomes. Gastrointest Endosc 2006; 63: 635-643

2 Cahen D, Rauws E, Fockens $P$ et al. Endoscopic drainage of pancreatic pseudocysts: long-term outcome and procedural factors associated with safe and successful treatment. Endoscopy 2005; 37: 977-983

3 Baron TH. Treatment of pancreatic pseudocysts, pancreatic necrosis, and pancreatic duct leaks. Gastrointest Endosc Clin N Am 2007; 17: 559-579, vii

4 Lawrence C, Howell DA, Stefan AM et al. Disconnected pancreatic tail syndrome: potential for endoscopic therapy and results of long-term follow-up. Gastrointest Endosc 2008; 67: 673-679

5 Beckingham IJ, Krige JE, Bornman PC et al. Endoscopic management of pancreatic pseudocysts. Br J Surg 1997; 84: 1638-1645

\section{Bibliography}

DOI $10.1055 / \mathrm{s}-0030-1255902$

Endoscopy 2011; 43: E45-E46

(c) Georg Thieme Verlag KG Stuttgart · New York . ISSN 0013-726X

\section{Corresponding author}

\section{Topazian, MD}

Mayo Clinic

200 First Street SW

Rochester MN 55905

USA

Fax: +1-507-2663939

topazian.mark@mayo.edu 